list of seventy-nine disabilities treated in that way, and included we find three cases of suppuration after enucleation of the eye, and one case of suppuration in the lacrymal sac. As regards the first-named condition, the ozone appears to have acted well and promptly; but in the last-named no result was noted after twenty-one applications, and the sac was eventually removed.

\title{
Cutaneous Reactions
}

An interesting paragraph in the April number of American Medicine deals with the effect of the administration of certain drugs upon the different skin reactions. From recent researches it appears that normal individuals react positively to the luetin test after the administration of sixty or more grains of potassium iodide. Tuberculin reactions are intensified after iodides or bromides have been given. It is clearly of importance to distinguish between skin reactions of specific origin and those due to the administration of drugs. Indeed, it is by no means unlikely that failure to recognize the influence of medicines ingested may account in part for the divergent results obtained by observers with the luetin reaction and similar diagnostic tests.

\section{ABSTRACTS}

\section{I.-GUMMATA}

(1) Werner, F. (Jena).-Symmetrical gumma formation in the orbits. (Ueber symmetrische Gummibildung der Orbita.) Klin. Monatsbl.f. Augenheilk., March-April, I9I4.

(2) Pissarello, C.-A case of ulcerating gumma of the lid due to late hereditary syphilis. (Sopra un caso di gomma ulcerata delle palpebre, manifestazione sifilitica ereditaria tardiva.) Arch. di Ottalm., July, 1916.

(1) Werner reports the following case:-A healthy married woman, fifty years of age, complained of a left-sided headache of fourteen days' duration. There was redness and swelling of the lower lid, towards the external canthus, but no tenderness. A small tumour, about the size of a bean, could be felt on the outer end of the lower orbital margin. It was believed to be fibro-sarcoma, and was excised. A year later the patient returned with a similar tumour in the right orbit. Meanwhile the original growth had been found to be a granulation tumour, and a positive Wassermann reaction had been obtained. Gumma was therefore suspected, and, under salvarsan treatment, the new growth disappeared. The case serves to remind 